\title{
Improved size-tunable preparation of polymeric nanoparticles by microfluidic nanoprecipitation
}

\author{
Florence Bally ${ }^{\mathrm{a}, 1}$, Dhiraj Kumar Garg ${ }^{\mathrm{b}}$, Christophe A. Serra ${ }^{\mathrm{a}, *}$, Yannick Hoarau ${ }^{\mathrm{b}}$, Nicolas Anton ${ }^{\mathrm{c}}$, \\ Cyril Brochon ${ }^{\mathrm{d}}$, Dambarudhar Parida ${ }^{\mathrm{a}}$, Thierry Vandamme ${ }^{\mathrm{c}}$, Georges Hadziioannou ${ }^{\mathrm{d}}$

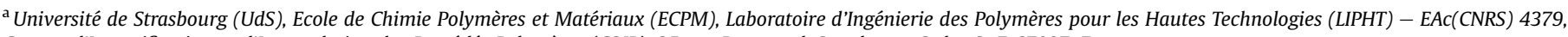 \\ Groupe d'Intensification et d'Intrapolation des Procédés Polymères (G2IP), 25 rue Becquerel, Strasbourg Cedex 2, F-67087, France \\ ${ }^{\mathrm{b}}$ Université de Strasbourg (UdS), Institut de Mécanique des Fluides et des Solides (IMFS) - CNRS, 2 rue Boussingault, Strasbourg, F-67000, France \\ ${ }^{\mathrm{c}}$ Université de Strasbourg (UdS), Faculté de Pharmacie, Laboratoire de Conception et Application de Molécules Bioactives, équipe de Pharmacie Biogalénique - CNRS 7199, \\ 74 route du Rhin BP 60024, Illkirch Cedex, F-67401, France \\ ${ }^{\mathrm{d}}$ Université de Bordeaux 1, Ecole Nationale Supérieure de Chimie, de Biologie E de Physique (ENSCBP), Laboratoire de Chimie des Polymères Organiques (LCPO) - CNRS 5629, \\ 16 av., Pey-Berland, Pessac Cedex, F-33607, France
}

\section{A R T I C L E I N F O}

\section{Article history:}

Received 4 June 2012

Received in revised form

16 August 2012

Accepted 17 August 2012

Available online 23 August 2012

\section{Keywords:}

CFD numerical simulation

Microprocess

Nanoprecipitation

Polymeric nanoparticle

\begin{abstract}
A B S T R A C T
Size-tunable polymeric nanoparticles have been successfully produced by a microfluidic-assisted nanoprecipitation process. A multilamination micromixer has been chosen to fabricate continuously nanoparticles of methacrylic polymers. Various operating conditions, such as the polymer concentration, the amount of non-solvent and the characteristics of the raw polymer (molecular weight and architecture: linear vs. branched) have been investigated. Their influences on the final particle size, ranging from 76 to $217 \mathrm{~nm}$, have been correlated to the mechanisms leading to the formation of nanoparticles. In this type of microfluidic device, mixing mainly operates by diffusion mass transfer, helped by hydrodynamic focusing. The effect of micromixing on the size of particles has also been shown experimentally and supported by a computational fluid dynamics (CFD) study. A mixing criterion has been defined and numerically calculated to corroborate the effect of the flow rate of polymer solution on the particles size. An increase in the polymer solution flow rate increases the value of this mixing criterion, resulting in smaller nanoparticles.
\end{abstract}

Crown Copyright $\odot 2012$ Published by Elsevier Ltd. All rights reserved.

\section{Introduction}

The fabrication of nanoparticles has become an increasingly attractive research field in recent years [1-3] and may have interesting properties for pharmaceutical applications, such as diagnostics or therapeutics [4-8]. When used as drug carriers, polymeric nanoparticles, defined as solid submicron colloidal particles, provide an improved circulation and biodistribution into the body, as well as high drug loading and release rates [9]. Different techniques have been developed to fabricate polymeric nanoparticles, in the form of nanocapsules [10], corresponding to

\footnotetext{
* Corresponding author.

E-mail address: ca.serra@unistra.fr (C.A. Serra).

1 Present Address. Institute of Functional Interfaces, Karlsruhe Institute of Technology, Hermann-von-Helmholtz-Platz 1, Eggenstein-Leopoldshafen, D-76344, Germany.
}

cavities surrounded by a polymeric membrane, or nanospheres [11], being polymer matrix-type particles. In this study, we focused on the formation of polymeric nanospheres, named nanoparticles in the following. Although nanoparticles can be produced by emulsion polymerization, this process may lack reproducibility and is restrictive to the chemical nature of the polymer that is used. An alternative is the fabrication of nanoparticles from a preformed polymer solution by solvent-displacement [12-14]. The precipitation of the preformed polymer occurs by dispersing the polymer solution in a large amount of a non-solvent. Based on the difference of solubility of the polymer in the solvent compared to the nonsolvent, nanoprecipitation produces nanoparticles via a one-step experimental process. By this technique, the solvent of the polymer solution (tetrahydrofuran, acetone...) is fully miscible with the non-solvent (usually water).

Although the process is now experimentally well-established, the mechanism responsible for the formation of the nanoparticles is still under question [11]. Several studies have contributed to the 
in-depth understanding of nanoprecipitation process, as initiated by Stainmesse et al. in 1995 [15]. He demonstrated that submicron particles can be formed at moderate polymer concentration when the volume of solvent (compared to non-solvent) is low enough. Recently, Mora-Huertas [11] suggested classifying the contributions according to two schools of thought: nanoprecipitation relying on a dispersion mechanism such as spinodal decomposition, also classified as a 'mechanical mechanism', or on a classical nucleation process, due to chemical instability. Both mechanisms agree with the fact that the suspension of particles is formed in the metastable region of the phase diagram, between the binodal (corresponding to the miscibility-limit) and the spinodal (being the stability-limit) curves. 'Mechanical' processes involve the breaking up of the polymer solution into 'droplets' and their dispersion in the non-solvent [16-19]. The breaking up of the polymer solution has been attributed to turbulences or instabilities at the interface between the two phases during solvent diffusion. Due to the miscibility of both phases, eddies of solvent at the interface may continue to break the droplets into smaller droplets until forming submicron droplets. This rapid process stops when the solvent flows away from the droplets, inducing polymer precipitation. In that case, the formation of polymer nanoparticles is due to the aggregation of the macromolecules present in the droplet. On the contrary, nanoparticles may nucleate since solvent diffusion produces regions of local supersaturation [20-22]. Supersaturation $(s)$ is defined by $s=C /$ $C^{*}$, where $C$ is the concentration of the polymer (in the final mixture) and $C^{*}$ its maximum concentration in the same solvent. This state corresponds to a chemical instability of the system, which is responsible for the presence of nuclei in the dispersed medium. After nucleation, particle growth is attributed to the capture of soluble macromolecules present near the nuclei, as it occurs for classical crystallization process. Aggregation of nuclei or growing particles is also possible at high concentration. In that context, Ganachaud et al. [23] correlated previous experimental results with the 'Ouzo effect', already described for liquid-liquid nucleation [24].

To the best of our knowledge, no study shows relevant experimental evidences that enable to conclude on a unique interpretation of nanoprecipitation process. Both mechanisms probably occur simultaneously, maybe at different levels depending on the concentration and the supersaturation state. At low polymer concentration and high supersaturation, it is reasonable to expect nucleation phenomenon, whereas at very high polymer concentration and low supersaturation, 'mechanical' mechanism is possible. Anyway, both mechanisms require efficient mixing of the polymer solution with the non-solvent to fabricate nanoparticles. Nanoprecipitation $[20,25]$ is usually performed via one-pot pouring of the polymer solution into the non-solvent, or by dropwise addition of one phase into the other. Recently, microfluidic processes, using a hydrodynamic flow-focusing set-up [26,27] or a confined impinging jet reactor [28-30], have emerged to improve the mixing of the two phases.

In light of the development of a continuous-flow microprocess, going from monomer solution to polymer recovery in the form of nanoparticles [31], we performed microfluidic-assisted nanoprecipitation. In this study, we focus on the process unit corresponding to the formation of poly(methyl methacrylate)-based nanoparticles, using a multilamination micromixer. The effect of several operating parameters, as well as the nature of the polymer, on the size of the nanoparticles has been investigated. Since the mixing operating into the microfluidic device was fundamental, computational fluid dynamics simulations have been performed to see how size-tunable nanoparticles can be obtained through this convenient microprocess.

\section{Experimental section}

\subsection{Materials}

2-ethyl bromoisobutyrate (Sigma Aldrich) initiator was distilled under vacuum prior to use. Methyl methacrylate (MMA, Sigma Aldrich) was passed through an alumina column (Merck) to remove inhibitor. 2-(2-bromoisobutyryloxy)-ethyl methacrylate (BIEM) was synthesized as previously described [32]. Cremophor ELP® (polyoxiethylated-35 castor oil, a non-ionic surfactant, BASF) was kindly provided by Laserson (Etampes, France). Ultrapure water for nanoprecipitation was obtained by passing through osmolizer and filtered prior to use. All other chemicals and solvents were commercially obtained (Sigma Aldrich) and used as received.

\subsection{Synthesis and characterization of MMA-based polymers}

Linear and branched polymers were synthesized by atom transfer radical polymerization. MMA (and BIEM for the synthesis of branched polymers) were polymerized in a Schlenk reactor at $60{ }^{\circ} \mathrm{C}$, under argon atmosphere, in the presence of copper (I) bromide, 1,1,4,7,10,10-hexamethyltriethylenetetramine, 2-ethyl bromoisobutyrate and dimethylformamide. Polymers, with various molecular weights and branching rates, were analyzed by Gel Permeation Chromatography (GPC) in THF (flow rate of $1 \mathrm{~mL} /$ min, $35^{\circ} \mathrm{C}$ ): a PL-GPC 120 platform equipped with a Shimadzu LC$10 \mathrm{AD}$ liquid chromatograph, a column (PL-gel $5 \mu \mathrm{m}$ MIXED-C, $300 \mathrm{~mm}$ ) and a PL-Refractive Index detector. Molecular weights are reported in poly(methyl methacrylate) (PMMA) standards for RI detection (see Supporting Information for GPC chromatograms). Polymer samples were also analysed by ${ }^{1} \mathrm{H}$ NMR (Bruker UltrashieldTM $300 \mathrm{MHz}$ NMR spectrometer) in $\mathrm{CDCl}_{3}$, with an internal lock on the signal of the solvent in order to determine the dried polymer content and the composition of the copolymer. (Table 1 ).

\subsection{Nanoprecipitation of methacrylic polymers}

When the polymerization reaction was stopped, the polymer solution was diluted with THF containing a non-ionic surfactant (Cremophor ELP ${ }^{\circledR}$ ) to achieve a final polymer solution concentration ranging from 1 to $5 \mathrm{wt} \%$. The mass ratio between surfactant and dried polymer kept constant at 0.5 . For the batch nanoprecipitation process, the polymer solution was added dropwise into water under continuous stirring at $500 \mathrm{rpm}$. For the continuous-flow nanoprecipitation process, the diluted polymer solution and the water as the non-solvent were separately pumped (307 SC HPLC Gilson piston pumps) and nanoprecipitation occurred within the (micro)mixer, consisting of either a T-junction (inner diameter: $1.6 \mathrm{~mm}$, Swagelock) or a High Pressure Interdigital Multilamination Micromixer (HPIMM) (see Fig. 1 for precise geometry and dimensions, IMM, Mainz, Germany). The suspension of nanoparticles was collected at the outlet of the micromixer.

\section{Table 1}

Macromolecular characteristics of the polymers used for the formation of nanoparticles. Linear polymers are poly(methyl methacrylate)s and branched polymers are synthesized from methyl methacrylate and 2-(2-bromoisobutyryloxy)-ethy methacrylate (BIEM). The percentage of BIEM among the total number of repeating units is mentioned for branched samples.

\begin{tabular}{lcl}
\hline Architecture & $M_{\mathrm{n}, \mathrm{GPC}-\mathrm{RI}}(\mathrm{g} / \mathrm{mol})$ & PDI $_{\mathrm{GPC}-\mathrm{RI}}$ \\
\hline Linear A & 7900 & 1.87 \\
Linear B & 17800 & 1.32 \\
Linear C & 23000 & 1.30 \\
Branched (7\% BIEM) & 7900 & 1.44 \\
Branched (13\% BIEM) & 7500 & 1.55 \\
\hline
\end{tabular}




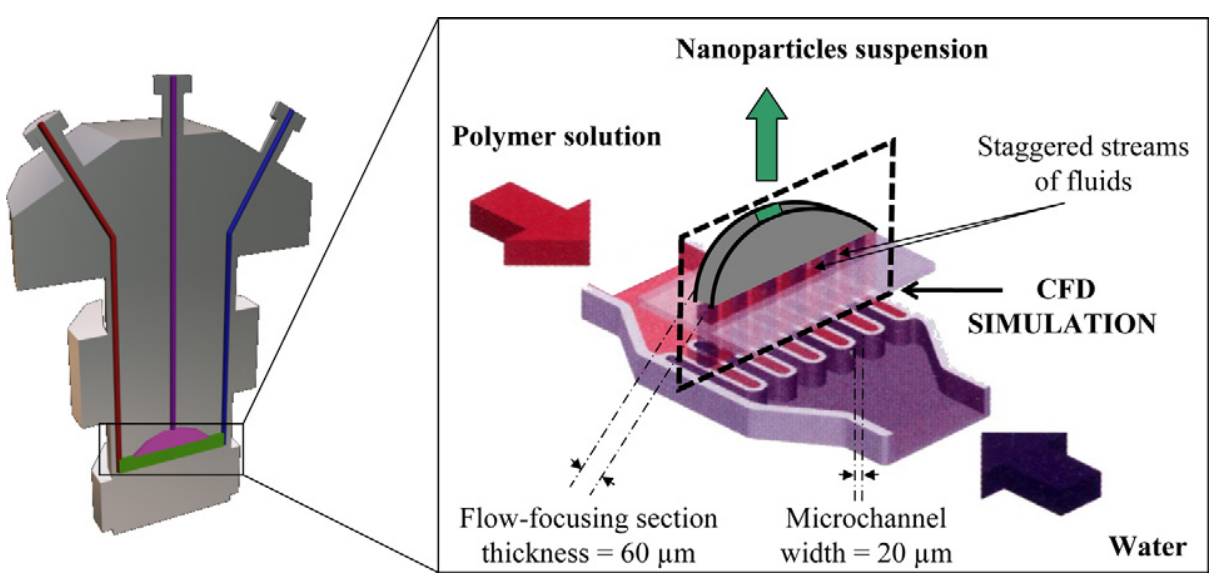

Fig. 1. Overview of HPIMM inner microstructure, used for nanoprecipitation.

\subsection{Characterization of nanoparticles suspension}

The diameter of the polymeric nanoparticles was determined by dynamic light-scattering (Malvern NanozS instrument). The $4 \mathrm{~mW}$ Helium-Neon laser, operates at $633 \mathrm{~nm}$, with a scatter angle fixed at $173^{\circ}$ and a constant temperature of $25^{\circ} \mathrm{C}$. Three measurements were performed for each sample. In this study, intensity-average particle diameter has been chosen to describe the size of the nanoparticles and only samples having a polydispersity index of particle size

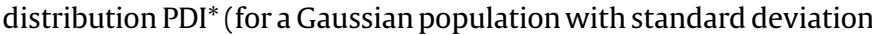
$\sigma$ and mean particle size $x_{\mathrm{PCS}}, \mathrm{PDI}^{*}=\sigma^{2} / x_{\mathrm{PCS}}{ }^{2}$ is the relative variance of the distribution) lower than 0.3 (which is the limit to consider a monodisperse sample) have been considered.

The cloud point of the polymer solution has been determined by titration of polymer solution with water until the mixture turned milky. The composition at the cloud point is the volume ratio of the polymer solution over the total volume of the mixture (volume of polymer solution and volume of added water) when turbidity appears.

\subsection{Computational fluid dynamics (CFD) study}

Computational fluid dynamics simulations were done using a commercial CFD software package CFD-ACE+ (ESI Group), which consists of CFD-GEOM, CFD-ACE and CFD-VIEW. The geometry was built using CFD-GEOM and structured meshing was done. To capture the significant disturbances/mixing pattern throughout the geometry, a fine mesh (about 230000 cells) was used. To keep the numerical diffusion low enough, second order Upwind method was chosen for all variables. Due to the presence of a symmetry plane in the thickness of the microstructure, the hydrodynamics was modeled in half of the flow-focusing section at steady state and simulated in CFD-ACE. As reported for interdigital micromixers [33], the numerical results presented in this paper were obtained by solving the incompressible Navier-Stokes equation:

$\frac{\partial u_{i}}{\partial t}+\left(u_{i} \cdot \nabla_{i}\right) u_{i}=-\frac{1}{\rho} \nabla_{i} p+\frac{\eta}{\rho} \nabla^{2} u_{i}$

the equation of mass conservation for incompressible fluids:

$\nabla_{i} u_{i}=0$

and a convective-diffusion equation for the THF concentration field (this concentration being the scalar):

$\frac{\partial c}{\partial t}+\left(u_{i} \cdot \nabla_{i}\right) c=D \nabla^{2} c$ by means of finite-volume method, $i$ being the coordinate in the orthonormal system, $u_{i}, \rho, \eta, D, p$ and $c$ being respectively the fluid velocity, density, viscosity, diffusivity coefficient, pressure and THF concentration. The density $\left(890 \mathrm{~kg} / \mathrm{m}^{3}\right)$, kinematic viscosity $\left(6.6 .10^{-7} \mathrm{~m}^{2} / \mathrm{s}\right)$ and diffusivity coefficient $\left(2.10^{-10} \mathrm{~m}^{2} / \mathrm{s}\right)$ of the polymer solution were modeled as constant in all the simulations. The value of scalar was bounded between 0 and 1 . The convergence criteria, defined as the ratio of the sum of residuals at all nodes between any two iterations, was $10^{-4}$ for all the variables and was found to be suitable as there was no improvement in the accuracy of the results despite decreasing this value. Different values of velocity were specified for each inlet type (depending on the experimental flow rates that were modeled). The boundary condition for the velocity of each inlet was specified to be constant and only in the direction of the flow. The flow was allowed to be developed before entering the flowfocusing section. A no slip boundary condition was specified at walls. The gradient of scalar at the wall was also specified to be zero to model the impervious nature of the wall. Atmospheric pressure was defined at the flow-focusing outlet. The temperature was constant and equal to $300 \mathrm{~K}$. No heat transfer was considered. All the post-processing of the results was done in CFDVIEW.

\section{Results and discussion}

\subsection{Influence of operating parameters and polymer characteristics} on the size of nanoparticles

Polymeric nanoparticles have been fabricated by nanoprecipitation via a continuous-flow microprocess. A High Pressure Interdigital Multilamination Micromixer (HPIMM) was chosen to mix the solution of methacrylic polymer (prepared in THF) with water. In this microfluidic device, fluid lamellae of $20 \mu \mathrm{m}$ (polymer solution and water) are alternatively staggered before entering a flow-focusing section, where the width of fluid lamellae is decreased (Fig. 1). By operating at relatively a low flow rate, this micromixer is characterized by a Reynolds number in the laminar regime. Furthermore, the dominant mixing phenomenon is diffusion mass transfer. The diffusion of the species is helped by a high contact surface between the multiple lamellae and by the flowfocusing section. The diffusion of the species within the microstructure thus enables to get the required dispersion of the polymer in a non-solvent and therefore to recover a suspension of nanoparticles at the outlet of the micromixer. 
The non-solubility of the polymer in the final mixture is a key parameter to fabricate nanoparticles. Therefore, the effect of the proportion of solvent and non-solvent constituting the final dispersive medium, and defined by the parameter $R$ in Equation (4), has first been investigated.

$$
R=\frac{\text { Volume Flow Rate(Water })}{\text { Volume Flow Rate(Polymer solution })}
$$

This parameter contributes to the number of particles that are formed. When the nucleation mechanism is considered, increasing $R$ leads to higher supersaturation. Therefore, more nuclei appear which decreases the final particle size. If the 'mechanical' mechanism is followed, a higher value of $R$ increases the potential interface and more droplets are formed during phase separation. As a consequence, the local concentration of the polymer is decreased which leads to smaller nanoparticles. Due to the effect of $R$ on the final particle size, the operating parameters investigated below have always been tested at various values of $R$. In addition, the suspensions of nanoparticles were stabilized by a surfactant to limit subsequent coalescence of particles.

As early reported in the literature [15], the concentration of the preformed polymer largely affects the nanoparticles size. Polymer solutions with initial polymer concentrations $\left(C_{n}\right)$ from 1 to $5 \mathrm{wt} \%$ have been used to fabricate nanoparticles (at various $R$ ). As can be seen in Fig. 2, the particle size both depends on the concentration $C_{n}$ and on the value of $R$ (proportion of water in the final mixture). At low $R$, typically $R=3$, the particle size is very similar regardless of the concentration $C_{n}$. This observation is coherent with a nucleation and growth mechanism. At a given $R$, the maximal solubility of the polymer $\left(C^{*}\right)$ is constant but the number of nuclei and the rate of particle growth depend on the polymer concentration. As the nucleation rate increases with concentration, the particle size should decrease. However, since the polymer concentration is quite high ( $\geq 1 \mathrm{wt} \%$ ), growth phenomena are also favored by the proximity of polymer chains. Higher nucleation rate finally compensates with higher growth probability when initial polymer concentration increases. On the contrary, at high $R$, typically $R=10$, the size of the particles varies from 106 to $210 \mathrm{~nm}$ along the concentration $\left(C_{n}\right)$ range. This significant difference has been attributed to more aggregation at high polymer

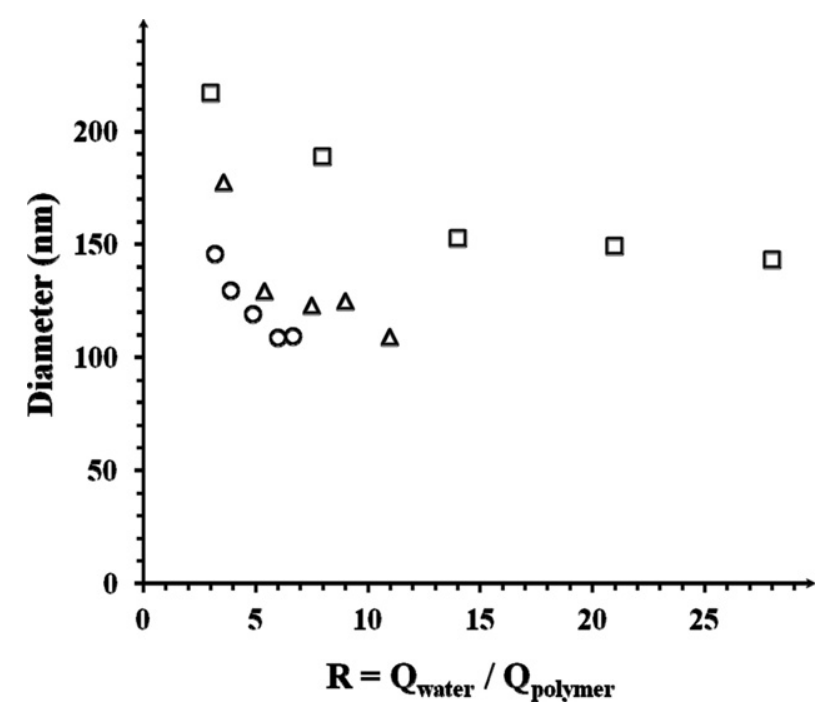

Fig. 2. Evolution of nanoparticles size with initial polymer concentration $C_{n}$ (polymer 'linear B'): $1 \mathrm{wt} \%(\square), 2 \mathrm{wt} \%(\Delta), 5 \mathrm{wt} \%(O)$ in THF, for various values of $R$ ( $R$ being the volume flow rate ratio between water and the polymer solution), at constant flow rate of polymer solution $=0.8 \mathrm{~mL} / \mathrm{min}$ (in HPIMM micromixer). concentration. At high $R$, more nuclei appear, and particle growth by capture of solute macromolecules occurs. However, aggregation of growing particles also contributes to the increase of particle size.

Polymers with three different molecular weights, ranging from 7900 to $23,000 \mathrm{~g} / \mathrm{mol}$, and various branching rates have been synthesized and precipitated to investigate the effect of polymer characteristics on the nanoprecipitation process. Suspensions of nanoparticles with various sizes, ranging from 76 to $177 \mathrm{~nm}$, have been fabricated, even if the polymer solutions have been prepared with constant weight fraction of polymer (1 wt\%) (see Supporting Information for numerical data). Due to the molecular weight difference between the different polymers, the number of chains varies from one polymer sample to the other, leading to various molar chain concentrations. Therefore, the evolution of the nanoparticles size has here been studied as a function of the molar chains concentration, to take the molecular weight of the sample into account. Fig. 3 shows that the molar chains concentration directly impacts the nanoparticle size for the different linear polymers. A similar tendency can be observed for branched polymers, which are denser than linear polymers at similar hydrodynamic volume (see also Supporting Information). These results are interesting from an engineering point of view, since whatever the macromolecular characteristics of the polymer are, various particles sizes can be reached by tailoring the molar chains concentration of the final sample.

Since the originality of this work mainly lies in the microprocess used to fabricate nanoparticles, the effect of the mixing process on the particles size has been studied. The mixing process may affect the production of nanoparticles [22]. A conventional T-junction, operating via bilamination mixing, has been compared to a multilamination micromixer. As expected, particles size was larger for bilamination mixing (Table 2 ). This result confirms the poor mixing in this type of devices. As a reference, nanoprecipitation has even been performed in a batch process, by dropwise addition of the polymer solution in water. The particle size is very close to the one obtained with the T-junction. Therefore, by working with an initial polymer concentration of $1 \mathrm{wt} \%$, fine mixing is a major issue to produce small nanoparticles. Additionally, it is worthy to notice that micromixer-assisted nanoprecipitation enables the production of small nanoparticles by using less non-solvent. Typically, $R=2$

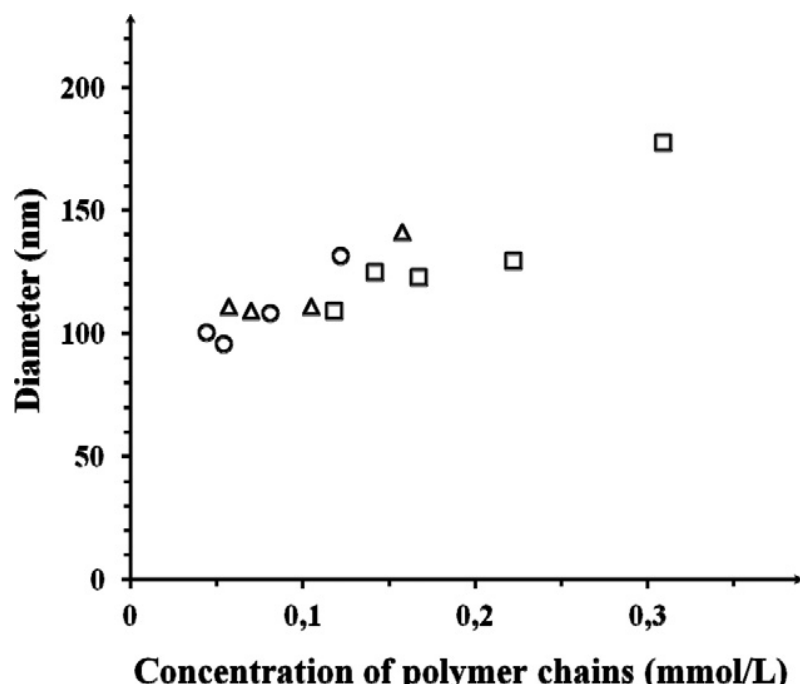

Fig. 3. Evolution of particle size (in $\mathrm{nm}$ ) as a function of molar concentration of polymer chains in the final solution (in $\mathrm{mmol} / \mathrm{L}$ ) for linear polymers with various molecular weights: $7900 \mathrm{~g} / \mathrm{mol}(\square), 17,800 \mathrm{~g} / \mathrm{mol}(\Delta), 23,000 \mathrm{~g} / \mathrm{mol}(\bigcirc)$. For each series of points, $R$ varied accordingly to Table S1 (in Supporting Information). 
Table 2

Evolution of particle size (in $\mathrm{nm}$ ) fabricated by different mixing processes, at various $R$. na corresponds to polydisperse samples.

\begin{tabular}{lllll}
\hline Mixer & $R=2$ & $R=3$ & $R=5$ & $R=10$ \\
\hline Batch & na & 251 & 244 & 245 \\
T-junction & na & na & 274 & 257 \\
HPIMM & 174 & 131 & 108 & 100 \\
\hline
\end{tabular}

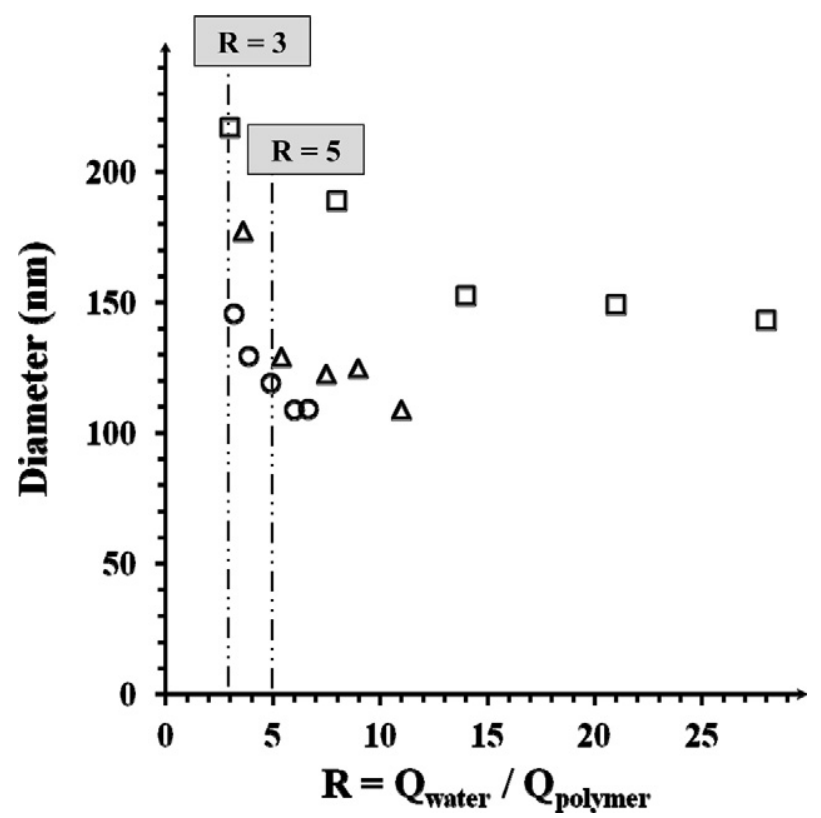

Fig. 4. Evolution of particle size (in $\mathrm{nm}$ ) obtained for various $R$ at different flow rates of polymer solution: $0.2 \mathrm{~mL} / \mathrm{min}(\square), 0.8 \mathrm{~mL} / \mathrm{min}(\Delta), 1.5 \mathrm{~mL} / \mathrm{min}(O)$. The vertical dashed lines corresponds to $R=3$ and $R=5$, which are the cases that are later numerically simulated.

leads to nanoparticles lower than $200 \mathrm{~nm}$ whereas at least $R=10$ is required for similar particles size in batch process. By the use of a micromixer, nanoprecipitation of polymer solution with concentrations up to $5 \mathrm{wt} \%$ can also be achieved, which is impossible in batch conditions (polydisperse samples). These improvements are of crucial importance for process intensification and are major advantages of this microprocess.

\subsection{Computational fluid dynamics to investigate micromixing}

We investigated in detail the effect of micromixing on the final particles' size by using the HPIMM at various flow rates. The initial polymer concentration was fixed to $1 \mathrm{wt} \%$, in order to limit particle growth by aggregation phenomenon and the solvent to nonsolvent ratio volume was changed as usual (various values of $R$ ). As can be seen in Fig. 4, nanoparticles of different sizes have been obtained for similar $R$ values when changing the polymer solution flow rate. The higher the flow rate, the smaller are the nanoparticles. This surprising result shows that the use of micromixer has a tremendous influence on the nanoprecipitation process. Since the concentration of the polymer solution was $1 \mathrm{wt} \%$ and the values of $R$ were equal or higher than 3 , it is reasonable to consider nucleation as the predominant mechanism operating in the formation of nanoparticles. In that case, mixing has a high influence on the final particle size since a fine mixing enables a homogeneous nucleation and avoids concentration gradients.

To observe nucleation, it has been determined experimentally that the maximum volume ratio between the polymer solution and the total solvent/non-solvent mixture should be 0.68 . This value corresponds to the appearance of the cloud point while slowly adding water to the polymer solution. As a consequence, if the volume ratio of THF (solvent of the polymer) in the total mixture is lower than this critical value, nucleation can occur. We used this critical value, and thus the criterion of possible nucleation, as an indicator of mixing in the following. An efficient mixing corresponds to a high volume of the microstructure with a THF concentration below this critical value, in the steady state.

Numerical simulations of the hydrodynamics have been performed within the flow-focusing section of the micromixer in order to see the influence of the flow rate of the polymer solution on mixing efficiency, while keeping $R$ constant $(R=3$ and then $R=5$, to operate at the same supersaturation state). Only the main flowfocusing section was modeled since most of the mixing occurs in this portion of the micromixer. As depicted in Fig. 5, different 2D cuts have been made within the $60 \mu \mathrm{m}$-thickness of the microstructure to have an overview of the mixing throughout the flowfocusing section. The wall of the microstructure corresponds to $z=0 \mu \mathrm{m}$ while $z=30 \mu \mathrm{m}$ corresponds to the middle of the flowfocusing section.

The views of hydrodynamics simulation of the different cuts at various flow rates of the polymer solution $\left(Q_{\text {polymer }}\right.$ equal to $0.2,0.8$, $1.5 \mathrm{~mL} / \mathrm{min})$ are shown in Table $3(R=3)$. The black area is the region where nucleation may occur (volume ratio between the polymer solution and the total solvent/non-solvent mixture being equal or lower than 0.68 ). It is a mixed region, as defined previously. By analyzing the different cuts, larger black areas are obtained at the higher flow rates of polymer solution. The most significant views are however the cuts at $z=10 \mu \mathrm{m}$ and $z=20 \mu \mathrm{m}$. These views are more important than the two others because they

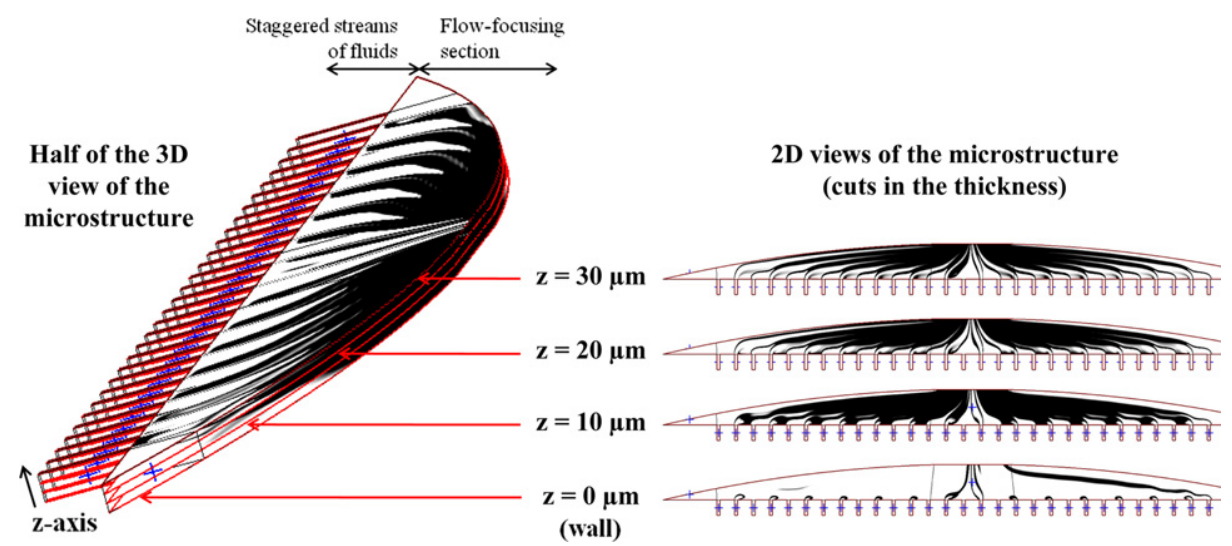

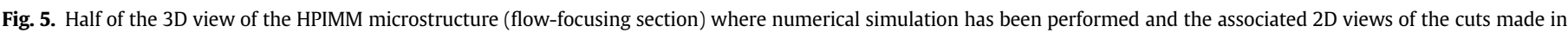
the microstructure (examples corresponding to $Q_{\text {polymer }}=0.2 \mathrm{~mL} / \mathrm{min}$ and $R=3$ ). 
Table 3

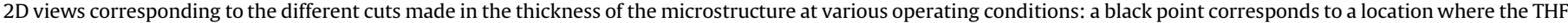
concentration is equal or below 0.68 (concentration of the cloud point).

\begin{tabular}{|c|c|}
\hline \multirow[t]{3}{*}{$z=0 \mu \mathrm{m}$} & $\begin{array}{l}Q_{\text {polymer }}=0.2 \mathrm{~mL} / \mathrm{min} \\
Q_{\text {water }}=0.6 \mathrm{~mL} / \mathrm{min}\end{array}$ \\
\hline & $\begin{array}{l}Q_{\text {polymer }}=0.8 \mathrm{~mL} / \mathrm{min} \\
Q_{\text {water }}=2.4 \mathrm{~mL} / \mathrm{min}\end{array}$ \\
\hline & $\begin{array}{l}Q_{\text {polymer }}=1.5 \mathrm{~mL} / \mathrm{min} \\
Q_{\text {water }}=4.5 \mathrm{~mL} / \mathrm{min}\end{array}$ \\
\hline \multirow[t]{3}{*}{$z=10 \mu \mathrm{m}$} & $\begin{array}{l}Q_{\text {polymer }}=0.2 \mathrm{~mL} / \mathrm{min} \\
Q_{\text {water }}=0.6 \mathrm{~mL} / \mathrm{min}\end{array}$ \\
\hline & $\begin{array}{l}Q_{\text {polymer }}=0.8 \mathrm{~mL} / \mathrm{min} \\
Q_{\text {water }}=2.4 \mathrm{~mL} / \mathrm{min}\end{array}$ \\
\hline & $\begin{array}{l}Q_{\text {polymer }}=1.5 \mathrm{~mL} / \mathrm{min} \\
Q_{\text {water }}=4.5 \mathrm{~mL} / \mathrm{min}\end{array}$ \\
\hline \multirow[t]{3}{*}{$z=20 \mu \mathrm{m}$} & $\begin{array}{l}Q_{\text {polymer }}=0.2 \mathrm{~mL} / \mathrm{min} \\
Q_{\text {water }}=0.6 \mathrm{~mL} / \mathrm{min}\end{array}$ \\
\hline & $\begin{array}{l}Q_{\text {polymer }}=0.8 \mathrm{~mL} / \mathrm{min} \\
Q_{\text {water }}=2.4 \mathrm{~mL} / \mathrm{min}\end{array}$ \\
\hline & $\begin{array}{l}Q_{\text {polymer }}=1.5 \mathrm{~mL} / \mathrm{min} \\
Q_{\text {water }}=4.5 \mathrm{~mL} / \mathrm{min}\end{array}$ \\
\hline \multirow[t]{3}{*}{$z=30 \mu \mathrm{m}$} & $\begin{array}{l}Q_{\text {polymer }}=0.2 \mathrm{~mL} / \mathrm{min} \\
Q_{\text {water }}=0.6 \mathrm{~mL} / \mathrm{min}\end{array}$ \\
\hline & $\begin{array}{l}Q_{\text {polymer }}=0.8 \mathrm{~mL} / \mathrm{min} \\
Q_{\text {water }}=2.4 \mathrm{~mL} / \mathrm{min}\end{array}$ \\
\hline & $\begin{array}{l}Q_{\text {polymer }}=1.5 \mathrm{~mL} / \mathrm{min} \\
Q_{\text {water }}=4.5 \mathrm{~mL} / \mathrm{min}\end{array}$ \\
\hline
\end{tabular}

appear twice in the microstructure, due to the symmetry of the micromixer. They also better characterize the inside of the flowfocusing section, contrarily to the view at $z=0 \mu \mathrm{m}$ showing particular conditions at the walls of the microstructure.

Since $R$ is the same for the three different cases of flow rates, we can conclude that higher nucleation occurs at higher polymer solution flow rates due to an improved mixing operating in the micromixer. This is coherent with the evolution of the nanoparticle size experimentally observed, the particles being smaller at high flow rates (due to more nucleation). To quantify the tendency observed in numerical simulations, we calculated a 'mixing criterion' defined as the percentage of mesh points having a THF

Table 4

Mixing criterion calculated by numerical simulations at various operating conditions.

\begin{tabular}{lccc}
\hline$Q_{\text {polymer }}(\mathrm{mL} / \mathrm{min})$ & 0.2 & 0.8 & 1.5 \\
$Q_{\text {water }}(\mathrm{mL} / \mathrm{min})$ & 0.6 & 2.4 & 4.5 \\
$\mathrm{R}$ & 3 & 3 & 3 \\
Mixing criterion (\%) & $\mathbf{5 1}$ & $\mathbf{6 7}$ & $\mathbf{7 3}$ \\
$Q_{\text {polymer }}(\mathrm{mL} / \mathrm{min})$ & 0.2 & 0.8 & 1.5 \\
$Q_{\text {water }}(\mathrm{mL} / \mathrm{min})$ & 1.0 & 4.0 & 7.5 \\
$\mathrm{R}$ & 5 & 5 & 5 \\
Mixing criterion (\%) & $\mathbf{6 1}$ & $\mathbf{7 1}$ & $\mathbf{7 7}$ \\
\hline
\end{tabular}

concentration equal or below the cloud point. In other words, this criterion corresponds to the volume percentage of the microstructure where nucleation is possible ('black volume'). As shown in Table 4, the mixing criterion increases with respect to the flow rate of polymer solution, holding for both $R$ values $(R=3$ and $R=5)$. This tendency is in agreement with experimental results (Fig. 4 ), since the particle size decreases while increasing the flow rate of polymer solution at a given $R$. Knowing that the value of $R$, and thus the supersaturation state, also influences the final particle size, this 'mixing criterion', resulting only from the hydrodynamics within the micromixer, enables the prediction of the evolution of the particle size at constant $R$ value.

\section{Conclusions}

This work has shown the possibility to tune the size of nanoparticles formed by a microfluidic-assisted nanoprecipitation process. The concentration of the polymer solution, the volume ratio between the non-solvent and the solvent as well as the macromolecular characteristics, such as molecular weight and architecture (linear and branched), have first been investigated using an HPIMM micromixer. The influence of these parameters on the particle size is coherent with a nucleation mechanism at the 
origin of the formation of nanoparticles. Additionally, micromixing has an effect on the nucleation process and leads to smaller particles. CFD numerical simulations have supported these results because improved mixing operates in the HPIMM at high flow rate of polymer solution. A 'mixing criterion' has even been suggested to quantify the mixing efficiency. It is defined as the volume percentage of the microstructure where nucleation may occur. This study offers interesting perspectives to the development of a microprocess that enables to go from monomer solution to the recovery of polymer in the form of a nanoparticles suspension. It would actually be possible to consider biomedical applications by using this micromixer-assisted nanoprecipitation process to formulate inline drug-loaded nanoparticles.

\section{Acknowledgments}

Authors would like to thank Anne Hebraud, Fabio Codari and Véronique Gernigon for helpful discussions. IMM institute is also acknowledged for providing the HPIMM and especially Dr. Bernd Werner and Daniel Metzke for technical data used for numerical simulations. The financial support by the ANR grant $\mathrm{n}^{\circ}$ 09-CP2D$\mathrm{DIP}^{2}$ is greatly appreciated.

\section{Appendix A. Supplementary data}

Supplementary data related to this article can be found at http:// dx.doi.org/10.1016/j.polymer.2012.08.039.

\section{References}

[1] Burda C, Chen X, Narayanan R, El-Sayed MA. Chem Rev 2005;105:1025-102

[2] Daniel MC, Astruc D. Chem Rev 2004;104:293-346.

[3] McBride JR, Dukes III AD, Schreuder MA, Rosenthal SJ. Chem Phys Lett 2010; 498:1-9.
[4] Allémann E, Gurny R, Doelker E. Eur J Pharm Biopharm 1993;39:173-91.

[5] Anton N, Benoit JP, Saulnier P. J Control Release 2008;128:185-99.

[6] Rao JP, Geckeler KE. Prog Polym Sci 2011;36:887-913.

[7] Soppimath KS, Aminabhavi TM, Kulkarni AR, Rudzinski WE. J Control Release 2001;70:1-20.

[8] Vauthier C, Bouchemal K. Pharmaceut Res 2009;26:1025-58.

[9] Moghimi SM, Hunter AC, Murray JC. Pharmacol Rev 2001;53:283-318.

[10] Mora-Huertas CE, Fessi H, Elaissari A. Int J Pharm 2010;385:113-42.

[11] Mora-Huertas CE, Fessi H, Elaissari A. Adv Colloid Interfac 2011;163:90-122.

[12] Leroux JC, Allémann E, Doelker E, Gurny R. Eur J Pharm Biopharm 1995;41: $14-8$.

[13] Fessi H, Piusieux F, Devissaguet JP, Ammoury N, Benita S. Int J Pharm 1989;55: R1-4.

[14] Fessi H, Devissaguet JP, Puisieux F, Thies C. US Pat 5,118,528 1992.

[15] Stainmesse S, Orecchioni AM, Nakache E, Puisieux F, Fessi H. Colloid Polym Sci 1995;273:505-11.

[16] Galindo-Rodriguez S, Allémann E, Fessi H, Doelker E. Pharmaceut Res 2004; 21:1428-39.

[17] Molpeceres J, Guzman M, Aberturas MR, Chacon M, Berges L. J Pharm Sci 1996;85:206-13.

[18] Quintanar-Guerrero D, Allémann E, Doelker E, Fessi H. Colloid Polym Sci 1997; 275:640-7.

[19] Thioune O, Fessi H, Devissagueta JP, Puisieux F. Int J Pharm 1997;146:233-8.

[20] Aubry J, Ganachaud F, Addad JPC, Cabane B. Langmuir 2009;25:1970-9.

[21] Beck-Broichsitter M, Rytting E, Lebhardt T, Wang X, Kissel T. Eur J Pharm Sci 2010;41:244-53.

[22] Lince F, Marchisio DL, Barresi AA. J Colloid Interf Sci 2008;322:505-15.

[23] Ganachaud F, Katz JL. Chem Phys Chem 2005;6:209-16.

[24] Vitale SA, Katz JL. Langmuir 2003;19:4105-10.

[25] Hornig S, Heinze T, Becer CR, Schubert US. J Mater Chem 2009;19:3838-40.

[26] Karnik R, Gu F, Basto P, Cannizzaro C, Dean L, Kyei-Manu W, et al. Nano Lett 2008;8:2906-12.

[27] Rhee M, Valencia PM, Rodriguez MI, Langer R, Farokhzad OC, Karnik R. Adv Mater 2011;23:H79-83.

[28] Johnson BK, Prud'homme RK. AIChE J 2003;49:2264-82.

[29] Lince F, Marchisio DL, Barresi AA. Chem Eng Process 2011;50:356-68.

[30] Nagasawa H, Aoki N, Mae K. Chem Eng Technol 2005;28:324-30.

[31] Bally F, Serra CA, Brochon C, Anton N, Vandamme T, Hadziioannou G. Macromol React Eng 2011;5:542-7.

[32] Bally F, Serra CA, Brochon C, Hadziioannou G. Macromol Rapid Comm 2011; 32:1820-5.

[33] Hardt S, Schönfeld F. AIChE J 2003;49:578-84. 